\title{
内頝動脈先端部より高位の
}

内頝動脈-後交通動脈分岐部動脈瘤に対するクリッピング術

-2 症例報告一

田中 秀一, 川西 昌浩, 杉江 亮
山田 誠, 横山 邦生, 伊藤 裕

\section{Two Cases of Microsurgical Clipping of Internal Carotid-Posterior Communicating Artery Aneurysm Located above the Internal Carotid Bifurcation}

Hidekazu Tanaka, M.D., Masahiro Kawanishi, M.D., Akira Sugie, M.D., Makoto Yamada, M.D., Kunio YokoYama, M.D., and Yutaka ITo, M.D.

Department of Neurosurgery, Ijinkai Takeda General Hospital, Kyoto, Japan

Summary: We report two cases of internal carotid-posterior communicating artery aneurysm (IC-PC AN) located above the IC bifurcation. The first case was a 51-year-old woman with subarachnoid hemorrhage (SAH) caused by a ruptured high-lying IC-PC AN projecting superiorly. The aneurysm was behind the arteries and perforators completely in the pterional transsylvian route; therefore, the clip was applied from the carotid-optic triangle confirming the blade tip of the clip through the supracarotid triangle. The second case was an 81-year-old man with SAH because of a ruptured high-lying ICPC AN projecting posteriorly. The aneurysm was obscured by arteries and the temporal lobe in the pterional transsylvian route, so was visualized and clipped by retracting the arterial structures and temporal lobe, similar to an anterior temporal approach.

IC-PC ANs above the IC bifurcation are located behind the surrounding structures in the operative field. Therefore, selection of the proper approach according to the anatomical location of the IC-PC AN and effective utilization of the space around the IC as the surgical window are important in such cases.

\section{Key words: \\ $\cdot \mathrm{IC}-\mathrm{PC}$ AN \\ - IC bifurcation \\ - clipping surgery}

Surg Cereb Stroke

(Jpn) 44: 212-217, 2016

\section{はじめに}

内澒動脈-後交通動脈分岐部動脈瘤 (internal carotid-posterior communicating aneurysm : IC-PC AN) は全脳動脈 瘤の 20-30\%を占め手術機会も多い2 ${ }^{23) 9)}$. 多くは内頝動脈 (IC)の後外側 (retrocarotid space) に存在し, pterional ap- proach で問題なくクリッピングが可能だが, 時に特殊で 困難なことがある ${ }^{212)}$. 今回, IC-PC AN が IC 先端部より も高位, 深部に位置し, 工夫を要した 2 症例を経験した. 手術の実際を示し, 解剖学的理解やアプローチにつき文献 的考察を加え報告する.

医仁会武田総合病院 脳神経外科(受稿日 2015. 7. 7) (脱稿日 2015. 12. 26) 〔連絡先： ₹ 601-1495 京都府京都市伏見区石田森南町 28-1 医 仁会武田総合病院 脳神経外科 田中秀一] [Address correspondence: Hidekazu TANAKA, M.D., Department of Neurosurgery, Ijinkai Takeda General Hospital, 28-1 Ishidamoriminami-machi, Fushimi-ku, Kyoto, Kyoto 601-1495, Japan] 


\section{\begin{tabular}{l|l} 
A & B \\
\hline C & D
\end{tabular}}

Fig. 1 A: CT scan on admission showing $\mathrm{SAH}$ in the right sylvian fissure and basal cistern.

B: Source images of 3DCTA revealing an IC-PC AN (white arrow) lying higher than the top of the IC (arrowhead). The black arrows indicate the origin of $\mathrm{A} 1$ and $\mathrm{M} 1$.

C, D: 3DCTA demonstrating a superiorly projected IC-PC AN (arrow) located higher than the IC bifurcation (arrowhead) (C: superior view, D: anterolateral oblique view).

SAH: subarachnoid hemorrhage, ICPC AN: internal carotid-posterior communicating artery aneurysm, 3DCTA: 3D-computed tomography angiography
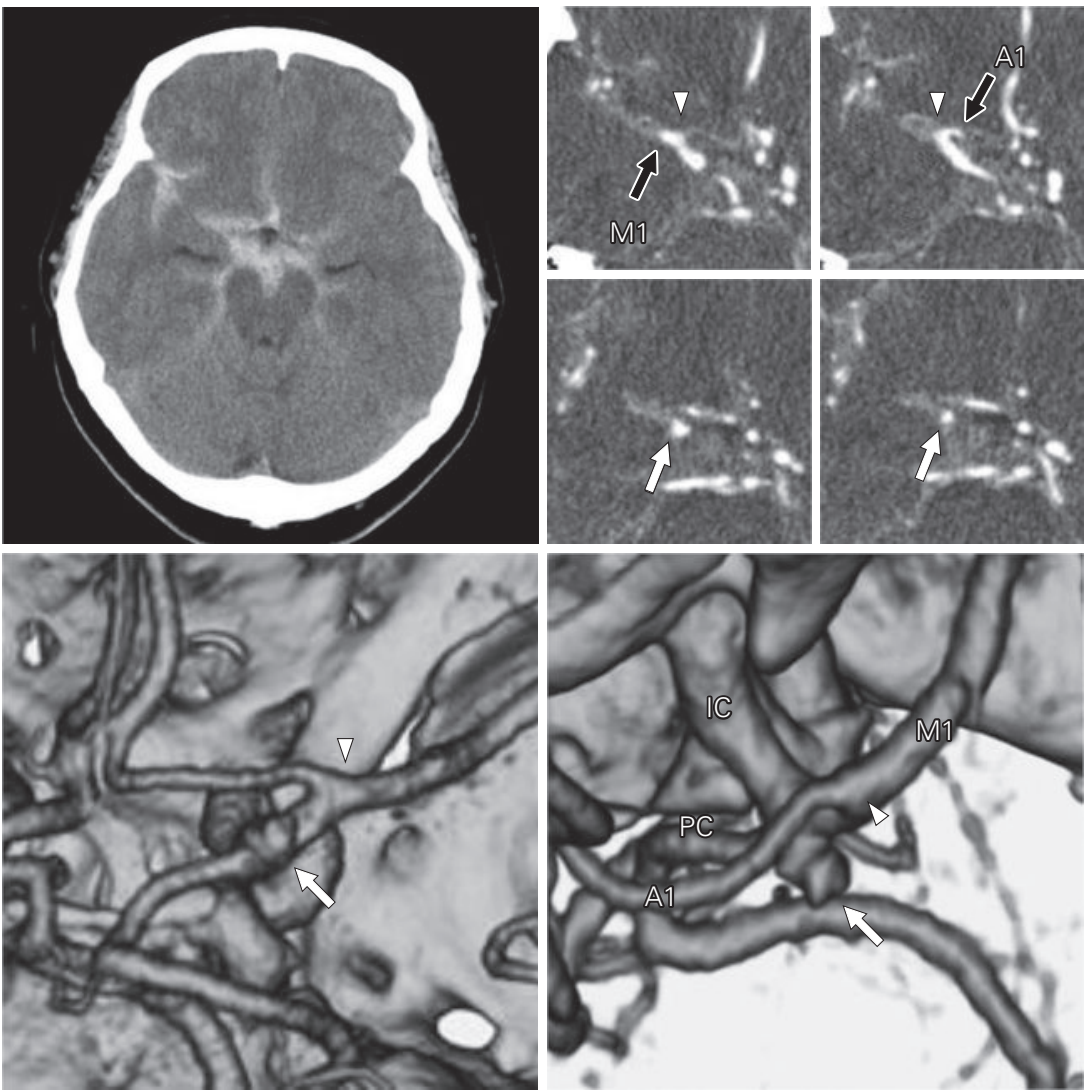

\section{症}

例

〈症例 1〉 51 歳, 女性.

主訴・現病歴：突然の頭痛があり，救急搬送された.

入院時現症 : Japan Coma Scale (JCS) 10, Glasgow Coma Scale (GCS) 14(E3V5M6), World Federation of Neurosurgical Surgeons (WFNS) grade II

画像所見：頭部 CT で脳底槽から右シルビウス裂にくも 膜下出血 (subarachnoid hemorrhage：SAH) を認め, 3DCTA とその原画像で後交通動脈 (PC) は fetal type で, 後上方にU 字蛇行した IC の頂点にblebを有する上向き $4 \mathrm{~mm}$ の IC-PC AN があり, IC 先端部より高位, 深部に 位置していた(Fig. 1).

手術所見 : distal transsylvian approach ${ }^{14)}$ で IC, 中大脳 動脈 (middle cerebral artery: MC), 前大脳動脈 (anterior cerebral artery：AC)を確保し, 蝶形頭頂静脈洞への流入 静脈を剝離してシルビウス裂を前頭葉側で広く開放した が, 瘤は IC 先端部の深部に位置し, carotid-oculomotor および carotid-optic triangle からは視認できなかった Fig. 2A). 前頭葉の上方牽引による premature rupture を危惧 して, IC, MC および ACを一時遮断し, supracarotid triangle で周囲の穿通枝越しに瘤と PC を露出したが，同部
から穿通枝を避けてのクリッピングは操作野が狭く深いた め困難で，L型 mini-size clip をbleb にかけるに留まった

(Fig. 2B, C). 血流遮断の解除で出血し, IC, MC, ACの 再遮断と point suction で全体像を確認のうえ, carotid-optic triangle から straight mini-size clip を挿入し, blade tip を supracarotid triangle から確認してクリッピングした (Fig. 2D)。総遮断時間 4 分.

術後経過：3DCTA で瘤は認めず, MRIで MC 穿通枝 域梗塞を認めたが(Fig. 3)，mRS 0 で独歩退院した。

〈症例 2〉 78 歳, 男性.

主訴・現病歴：突然の頭痛があり，救急搬送された。

入院時現症 : JCS 10, GCS 14(E3V5M6), WFNS grade II

画像所見：頭部 CT で脳底槽から右シルビウス裂に $\mathrm{SAH}$ 認め, 3DCTA とその原画像で PC は fetal type で，後上方にU 字蛇行した IC の頂点に後向き $5 \mathrm{~mm}$ の IC-PC AN があり，IC 先端部より高位，深部に位置して いた(Fig. 4).

手術所見： distal transsylvian approach でIC, MC, AC, PC を確保し, 蝶形頭頂静脈洞への流入静脈群を剝 離してシルビウス裂を側頭葉側で広く開放したが，瘤が 

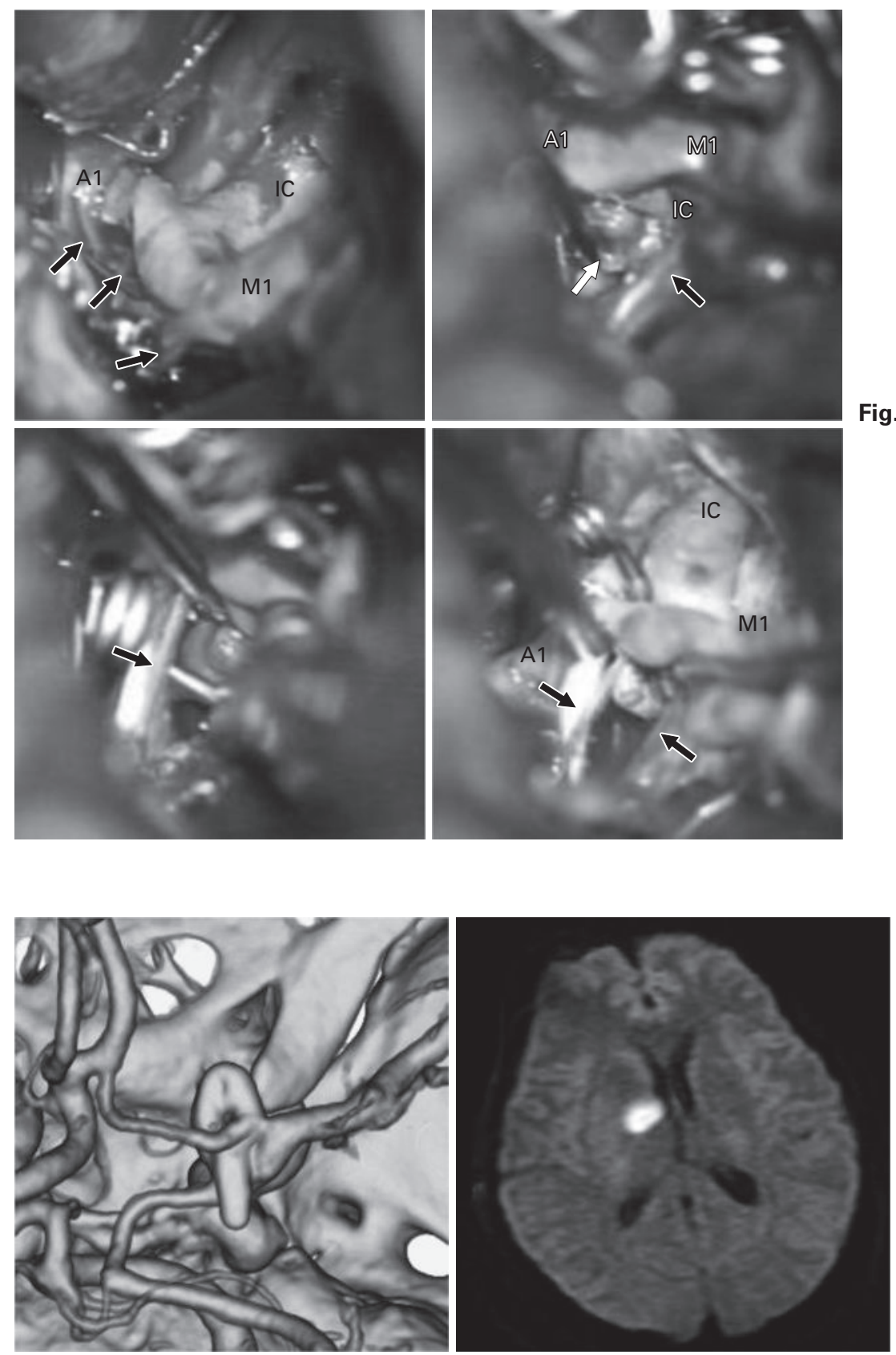

\section{\begin{tabular}{l|l} 
A & B \\
\hline C & D
\end{tabular}}

Fig. 2 Intraoperative microphotograms.

A: In the surgical field of the pterional transsylvian approach, the IC-PC AN was completely behind the surrounding arteries and perforators (black arrows).

B, C: The IC-PC AN (white arrow) was exposed through perforators (black arrows) in the supracarotid triangle (B), where placing a clip was difficult because of the restricted space (C).

D: A mini-size clip was applied from the carotid-optic triangle to occlude the ICPC AN, confirming the presence of the blade tip of the clip through the supracarotid triangle.

\section{A $\mid \mathbf{B}$}

Fig. 3 A: Postoperative 3DCTA showing clipping of the IC-PC AN.

B: Postoperative diffusion-weighted imaging of $\mathrm{MRI}$ showing an infarction of the genu of the internal capsule.
IC 先端部の高位, 深部ゆえ周囲構造物にさえぎられ carotid-oculomotor triangle での視認性と操作野は不十分で あった(Fig. 5A)。まず，前側頭動脈を全周性に剥離し IC から MCにかけての arterial archを内上方へ圧排のう え, 側頭葉を外側後方へ毫引して側頭葉に埋没した瘤を露 出した (Fig. 5B, C). premature rupture を危惧して IC, $\mathrm{MC}, \mathrm{AC}$ および $\mathrm{PC}$ を一時遮断したが, IC は動脈硬化が 高度で不完全閉鎖となった。瘤頚部の剝離中に出血したた め, ICへの temporary clip の追加と point suction での出 血管理下に straight clip 2 本でクリッピングした. 本例で
は側頭葉の後方牽引に加え, arterial archの圧排で瘤の高 さがIC 先端部に対して相対的に下がることで定型的な IC-PC AN と同様の術野が確保できた (Fig. 5D). 総遮断 時間 15 分.

術後経過：術後 3DCTA で瘤は認めず, MRI で IC 穿通 枝域と MC 灌流域に梗塞を認めた(Fig. 6). $\operatorname{mRS} 3$ でリハ ビリテーション病院に転院した。

考察

IC-PC AN クリッピングの難易度を決定する因子として 


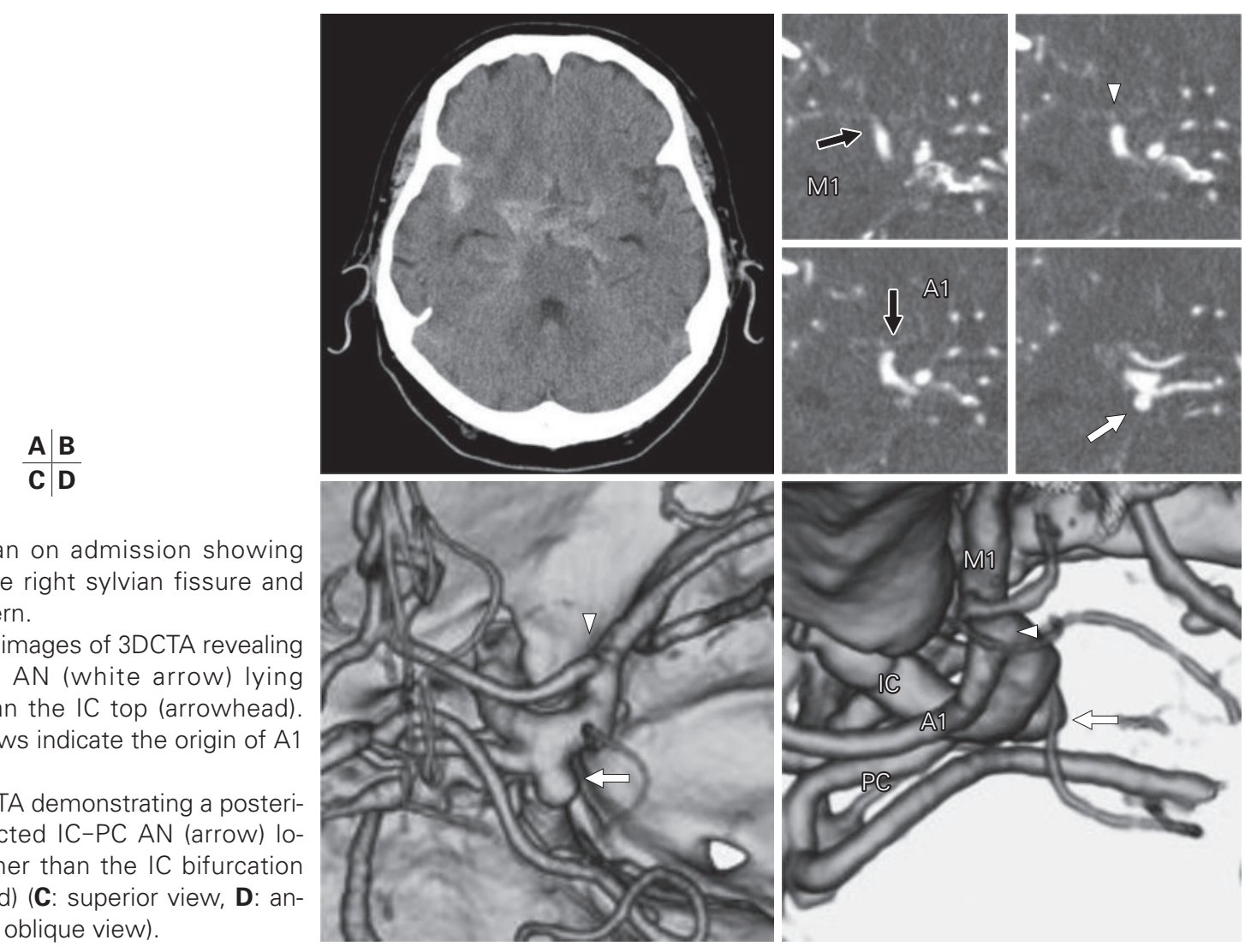

Fig. 4 A: CT scan on admission showing $\mathrm{SAH}$ in the right sylvian fissure and basal cistern

B: Source images of 3DCTA revealing an IC-PC AN (white arrow) lying higher than the IC top (arrowhead) Black arrows indicate the origin of $A$ and $\mathrm{M} 1$.

C, D: 3DCTA demonstrating a posteriorly projected IC-PC AN (arrow) located higher than the IC bifurcation (arrowhead) (C: superior view, D: anterolateral oblique view).

\section{A $\mid$ B}

Fig. 5 Intraoperative microphotograms.

A: In the surgical field of the pterional transsylvian approach, the IC-PC AN is obscured by surrounding arteries and the temporal lobe. A bridging vein $(*)$ was completely dissected as far as the sphenoparietal sinus.

B: The anterior temporal artery dissected free from the temporal lobe. Note that the fully exposed $\mathrm{M} 1$ is not kinked during the temporal retraction.

C: Retraction of the temporal lobe and arterial structures allows visualization of the IC-PC AN (arrow) embedded in the temporal lobe.

D: The IC-PC AN was clipped with two straight clips, sparing the anterior choroidal artery (arrowhead).
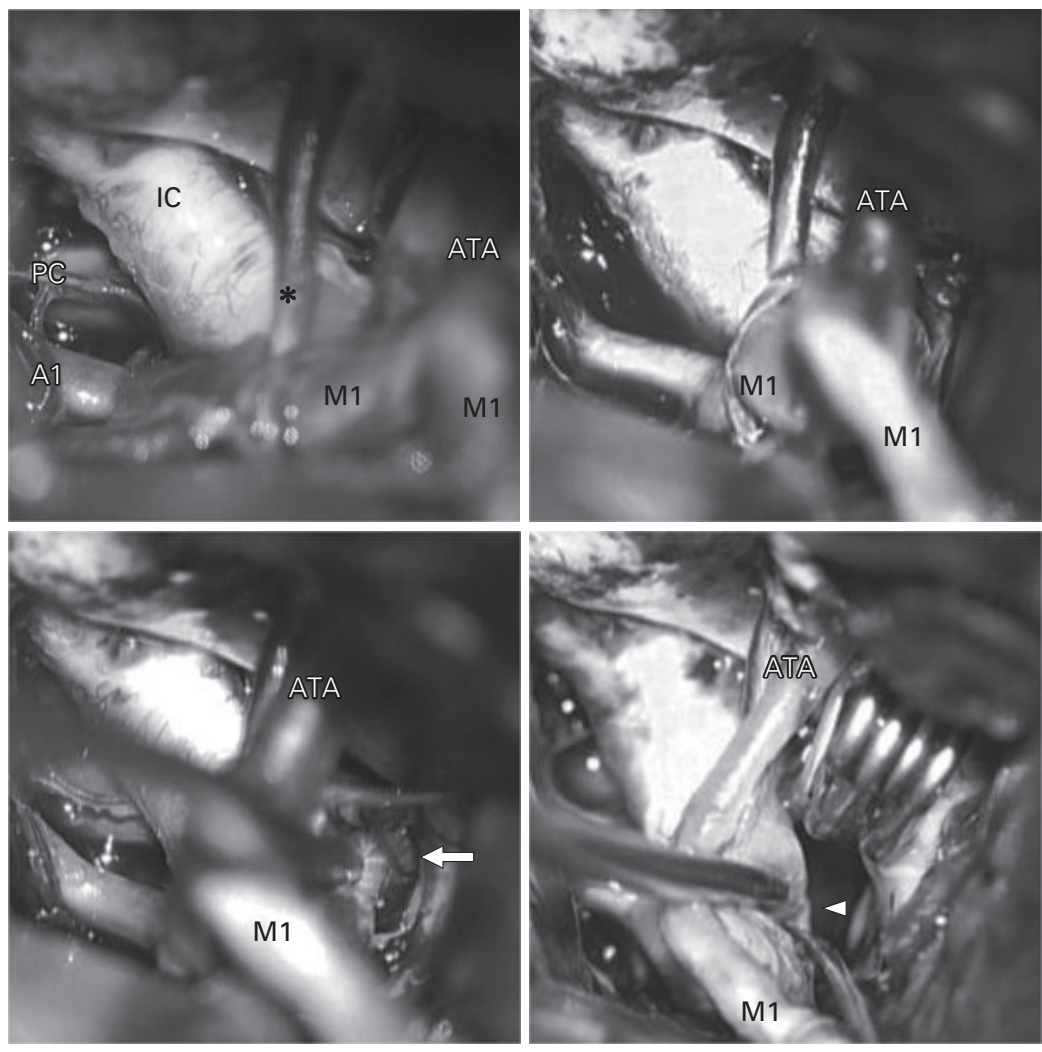

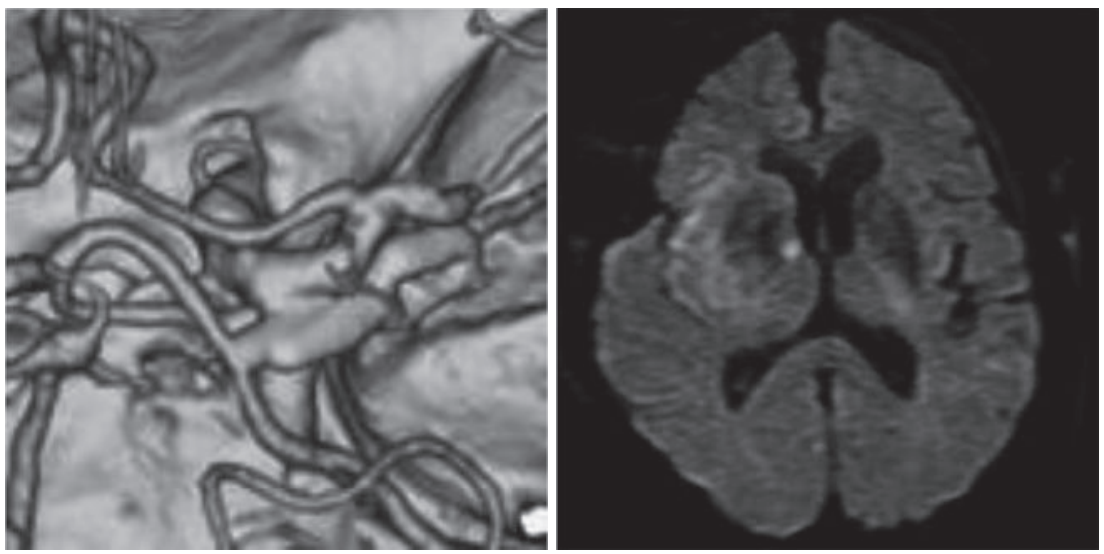

\section{A $\mid \mathbf{B}$}

Fig. 6 A: Postoperative 3DCTA showing clipping of the IC-PC AN.

B: Postoperative diffusion-weighted imaging of $\mathrm{MRI}$ showing infarction of the region around the middle cerebral and internal carotid arteries.

は, 瘤の大きさ, 発育方向, 形状, fetal type PC, 前床突 起との位置関係などの報告がある ${ }^{2) 8)}$ 。 また, 頭蓋底から の直接的な高さだけでなく, 術野での瘤と主幹動脈や穿通 枝, 神経との解剖学的位置関係が重要だが, 涉猟した限 り，IC-PC AN と IC 先端部との位置関係をもとに手技を 論じた報告はない. 通常の IC-PC AN は IC 先端部より低 位にあり, pterional approach で optico-carotid または carotid-oculomotor triangle にて問題なくクリッピングが可 能だが, 今回の 2 症例では後上方に蛇行した IC の頂点に fetal type PC が合流し, 瘤が IC 先端部より高位, 深部に 位置したため, 特に術野の展開に工夫を要した.

瘤が IC 先端部より高位, 深部に位置する場合, 頭蓋底 からの直接的な高さによらず, 術野で瘤が主幹動脈や穿通 枝の背後になり, 視認性と操作野の確保が重要とな る4) . さらに, IC-PC AN では, IC に隠れる後方成分の 程度につき術前評価が必要で, 後方成分がある場合は, 頚 部周囲が瘤や ICにさえぎられて盲点となり, subfrontal approach では対応困難で, 側頭葉を移動させて IC 後方の 術野を確保する必要がある ${ }^{3) 9)}$.

症例 1 の瘤は, 後方成分がなく上向きであり, 安易に前 頭葉側から接近したが，A1やM1，穿通枝に囲まれた狭 い術野でクリッピングに難渋した ${ }^{411)}$ 。高位, 深部病変に 対応可能な方法として, 側頭葉を後方に星引して retrocarotid space を広く確保し, MC と ICの外側から対処する anterior temporal approach ${ }^{5) 613)}$ があり，まずは試みるべ きであった。そのうえで対応困難な場合に限り，今回提示 した前頭葉側からの IC 周囲スペースの利用 ${ }^{1 / 6)}$ を考慮すべ きと反省される。

症例 2 の瘤は後方向きであり, 頭蓋底からの直接的な高 さはなく, IC 先端部より相対的に高く, 深い位置関係が 術野展開上の問題であった。当初より anterior temporal approach $^{516) 13)}$ に準じて術野を展開することで，定型的な 術野が確保できクリッピングし得たが, 側頭葉牽引の準備
とタイミング，程度に課題を残した。

以上の手技, 工夫でも視認性や操作野が不十分な場合 は, 追加の対策が必要で, 前床突起削除と硬膜輪切開によ る ICの可動化 ${ }^{5)}$, plical resection ${ }^{7)}$, temporary clipによ る IC の回転 ${ }^{12)}$, ミラーや内視鏡による観察などが検討さ れる.

今回の 2 症例は IC の動脈硬化性蛇行変形が原因で瘤が IC 先端部より高位, 深部に位置したと思われる. 高齢者 など動脈硬化の強い IC-PC AN は非定型的な場合があ り, 詳細な術前評価のうえ, アプローチを含め手術戦略に 十分な注意が必要である.

\section{結＼cjkstart語}

$\mathrm{IC}$ 先端部より高位, 深部の IC-PC AN のクリッピング では, 術野で瘤が周囲構造物の背後となるため視認性と操 作野の確保が重要となる。瘤の発育方向や周囲構造物との 解剖学的位置関係を評価し, 適切な approach を含めた手 術戦略が必要である。

著者全員は, 日本脳神経外科学会への COI 自己申告を 完了しています。本論文の発表に関して, 開示すべき COI はありません.

\section{文献}

1）藤岡正導：Pterional approachによる脳底動脈先端部動脈瘤 のクリッピング．脳外速報 21: 856-863, 2011

2) Golshani K, Ferrell A, Zomorodi A, et al: A review of the management of posterior communicating artery aneurysms in the modern era. Surg Neurol Int 1: 88, 2010

3）石川達哉：内澒動脈-後交通動脈瘤. 脳動脈瘤手術. 東京, 南江堂, 2010, pp173-189

4）石川達哉：内頝動脈先端部動脈瘤. 上山博康, 宝金清博(編 著）：脳動脈瘤手術。東京, 南江堂, 2010, pp190-197

5）勝野 亮, 谷川緑野, 太田仲郎, ほか：Anterior temporal approach と Extra-dural temporopolar approach一脳底動脈 
先端部動脈瘤および後方向き内頸動脈流に対して．脳外誌 19: 733-741, 2010

6) 勝野 亮, 谷川緑野, 宮崎貴則, ほか：未破裂脳動脈瘤に対 する anterior temporal approachの限界とその対応. No Shinkei Geka 41: 311-318, 2013

7）小寺俊昭, 菊田健一郎：Temporopolar approach による脳底 動脈分岐部動脈瘤クリッピング術. 脳外速報 21: 846-855, 2011

8) Sanai N, Caldwell N, Englot DJ, et al: Advanced technical skills are required for microsurgical clipping of posterior communicating artery aneurysms in the endovascular era. Neurosurgery 71: 285-94, 2012

9）清水宏明, 富永悌二：内澒-後交通動脈瘤の手術. No Shinkei Geka 37: 633-642, 2009

10）清水宏明, 冨永悌二：内頚動脈-後交通動脈瘤のクリッピン
グ. 脳外速報 22: 140-147, 2012

11）田中秀一, 川西昌浩, 伊藤 裕, ほか：後方発育した $\mathrm{A} 1$ 部 前大脳動脈瘤 5 例の治療経験. 脳卒中の外科 38: 409-414, 2010

12）田中雄一朗, 小林茂昭, 北沢和夫, ほか：内頸動脈後壁動脈 瘤クリッピング術の工夫一テンポラリークリップを用いた内 頸動脈の回転. 脳卒中の外科 27: 134-138, 1999

13）谷川緑野, 和田 始, 石崎智章, ほか：Distal transsylvian approachの変法としての Anterior temporal approach一脳 底動脈先端部動脈瘤に対して。脳卒中の外科 26: 259-264, 1998

14）谷川緑野，杉村敏秀，穂刈正昭，ほか：内頸動脈瘤手術にお けるDistal Transsylvian Approachのアドバンテージと技術 的ポイントーいわゆる Pterional Approach との違い. 脳卒 中の外科 32: 19-24, 2004 